\title{
Failure Characteristics and Mechanism of Multiface Slopes under Earthquake Load Based on PFC Method
}

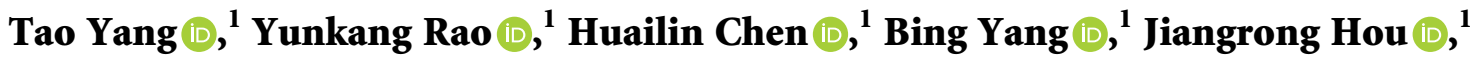 \\ Zihong Zhou $\mathbb{D}^{1}{ }^{1}$ and Haojiang Ding $\mathbb{D}^{2}$ \\ ${ }^{1}$ School of Civil Engineering, Southwest Jiaotong University, Chengdu 610031, China \\ ${ }^{2}$ China Railway Eryuan Engineering Group Co. Ltd., Chengdu 610031, China \\ Correspondence should be addressed to Bing Yang; yangb@home.swjtu.edu.cn
}

Received 19 May 2021; Accepted 9 August 2021; Published 19 August 2021

Academic Editor: Honglue Qu

Copyright (c) 2021 Tao Yang et al. This is an open access article distributed under the Creative Commons Attribution License, which permits unrestricted use, distribution, and reproduction in any medium, provided the original work is properly cited.

Understanding the failure mechanism and failure modes of multiface slopes in the Wenchuan earthquake can provide a scientific guideline for the slope seismic design. In this paper, the two-dimensional particle flow code $\left(\mathrm{PFC}^{2 \mathrm{D}}\right)$ and shaking table tests are used to study the failure mechanism of multiface slopes. The results show that the failure modes of slopes with different moisture content are different under seismic loads. The failure modes of slopes with the moisture content of 5\%, $8 \%$, and $12 \%$ are shatteringshallow slip, tension-shear slip, and shattering-collapse slip, respectively. The failure mechanism of slopes with different water content is different. In the initial stage of vibration, the slope with $5 \%$ moisture content produces tensile cracks on the upper surface of the slope; local shear slip occurs at the foot of the slope and develops rapidly; however, a tensile failure finally occurs. In the slope with $8 \%$ moisture content, local shear cracks first develop and then are connected into the slip plane, leading to the formation of the unstable slope. A fracture network first forms in the slope with $12 \%$ moisture content under the shear action; uneven dislocation then occurs in the slope during vibration; the whole instability failure finally occurs. In the case of low moisture content, the tensile crack plays a leading role in the failure of the slope. But the influence of shear failure becomes greater with the increase of the moisture content.

\section{Introduction}

The landslide caused by earthquakes is a common natural disaster in mountain areas [1-3]. Thousands of geological disasters have been triggered by the Wenchuan earthquake $\left(M_{S}=8.0\right)$ in western Sichuan, China, most of which (more than 60,000$)$ were landslides $[1,4]$. There are dozens of largescale landslides (>ten million $\mathrm{m}^{3}$ ) and more than 100 landslides with an area of more than $50,000 \mathrm{~m}^{2}[1,4]$. The landslide triggered by earthquakes is easy to cause a large number of casualties and economic loss. Therefore, it is important to study the failure mode and mechanism of slopes under earthquakes, which is of great significance to carry out earthquake defense and disaster reduction $[5,6]$.

Gang et al. [7] studied the dynamic failure modes of the bedding slope and counterbedding slope by the shaking table test. The results show that the main dynamic failure modes of the bedding slope include a vertical tensile crack at the rear of the slope, bedding slide of the strata along the weak intercalation, and rock collapse from the crest of the slope. In contrast, the dynamic failure modes of the counterbedding slope mainly include horizontal and vertical dislocation fissures, weak interlayer extrusion, and breakage at the crest. Liu et al. [8] performed a shaking table test to study the failure mode of slopes with horizontal soft and hard interbeddings under frequent microseisms. The failure mode of the slope is summarized as follows: creep-opening tensile cracks at the shoulder and opening pressing cracks at the slope bottom-developing secondary joints in the back end-developing secondary joints near the slope surfaceshearing in soft layers-slope sliding-accumulating blocks at the slope bottom. Li et al. [9] studied qualitatively the failure mechanism of the Hongshiyan landslide and the stability of the remnant slope combining with the on-site 
investigation and unmanned aerial vehicle (UAV) threedimensional imaging technologies. The failure mechanism is summarized as tension-crushing-shattering-sliding. Deng et al. [10] pointed out that the dynamic failure mode of the bedding rock slope with zigzag asperities is mainly characterized by the vertical tensile crack at the slope rear edge and integral slipping of the slope along the bedding surfaces, and the deformation pattern of the sliding surface was mostly determined by undulating angles and normal stress.

Hou et al. [11] used a two-dimensional particle flow program $\left(\mathrm{PFC}^{2 \mathrm{D}}\right)$ to investigate the dynamic process and hyperactivity mechanism of the loose deposit slope on the Ya'an-Kangding Expressway. The results show that the porosity of the surface slope generally increases with increasing seismic-wave loading time, while the porosity of the slope remains unchanged. Abe et al. [12] simulated and analyzed the dynamic characteristics of the slope model with different inclined weak interlayers by MPM (material point method). Chang and Tabada [13] used the discrete element model to simulate the avalanche caused by the Jiufengershan earthquake under various assumptions of rock properties, water table height, and boundary shear strength. Tang et al. [14] used the $\mathrm{PFC}^{2 \mathrm{D}}$ model to simulate the motion behavior of landslides caused by earthquakes.

The above studies are mainly based on a single free-face. However, there were some slopes damaged with multiple free-faces in the Wenchuan earthquake [15]. Yang et al. [16] simulated the failure process of double-side high and steep slope based on the continuous medium discrete element method (CDEM) combining with shaking table test data. The results show that the stress concentration appears at the top of the sliding mass at first, and then, a part of the tensionshear failure points appears, which expands from the top toward the toe of the sliding mass along the structural plane. Finally, the rupture of the toe leads to a landslide. Through model tests, the dynamic response of double-side slopes under strong earthquakes was studied by Xiao et al. [17]. It is found that the failure of different forms of double-side slopes under seismic waves is mainly caused by the repeated tension-shear effect and co-shear effect in both directions. Yang et al. [4] studied the failure process of a double-side slope with high moisture content under seismic load based on shaking table tests. The test results show that the slope failure has undergone a gradual deformation process, and the slope failure mode is a creeping landslide.

Through the analysis of present studies, it is shown that the failure mechanism of multiface slopes with different moisture content under earthquakes is not clear. The mechanism of crack formation and evolution during slope failure needs to be studied deeply and carefully. In this paper, the seismic instability characteristics and mechanism of three kinds of multiface slopes with different moisture content will be investigated based on $\mathrm{PFC}^{2 \mathrm{D}}$ and shaking table test.

\section{Test Details}

To verify the effectiveness of the numerical modeling, a set of shaking table model tests were carried out. A $3 \mathrm{~m} \times 2 \mathrm{~m}$ electro-hydraulic servo vibration table was used. The maximum displacement amplitude of the shaking table is $100 \mathrm{~mm}$, and the effective load is $20 \mathrm{t}$. It can output acceleration within the range of $0.05 \mathrm{~g}-1.5 \mathrm{~g}$, and the frequency range is $0.5-100 \mathrm{~Hz}$. The model box used in the test is a selfdeveloped rigid model box with smooth glass on one side, which is $2 \mathrm{~m}$ long, $0.8 \mathrm{~m}$ wide, and $1.5 \mathrm{~m}$ high, as shown in Figure 1. In this paper, the slope with multiple free-faces was simulated by a double-sided slope. In the model box, the double-sided slope is built by layered filling, and the filling height of each layer is $10 \mathrm{~cm}$. In the process of slope filling, the soil is rolled and compacted under constant external force to keep the same porosity in the slope. The final compactness of the model slope is $86.4 \%$, which is medium dense. The height of the double-side slope is $800 \mathrm{~mm}$, the width of the crest of the slope is $360 \mathrm{~mm}$, and the slope angle is $50^{\circ}$. The white sand with vertical zonal distribution is placed on the inner side of the glass wall to observe the deformation of the soil in the test. The test model is shown in Figure 2.

To monitor and study the dynamic characteristics and displacement of the slope, 15 acceleration sensors and 7 displacement sensors are arranged in the slope. At the same time, cameras are set on the front and side of the slope to record the whole process of slope failure, as shown in Figure 3. Sine wave was used to simulate excitation load. The test frequency is controlled at $3 \mathrm{~Hz}$, and the amplitude is increased step by step from $0.1 \mathrm{~g}$ to $0.6 \mathrm{~g}$ (g is gravity acceleration). The failure of the slope is observed within the loading time of $12 \mathrm{~s}$. If there is no obvious damage, it is found that the slope is stable under this loading amplitude.

\section{Numerical Models of PFC}

The numerical simulation method of particle flow (Particle Flow Code) is based on the discrete element method proposed by Cundall [18]. This method can be used to study the mechanical properties and behavior of media from a microscopic point of view.

3.1. Constitutive Model and Parameters. In the two-dimensional PFC model, the particles are represented by a rigid disk, and these discrete particles are subjected to force only in the contact part. When the force acting on the contact point is larger than the contact strength, these particles can be separated from each other, making the model object deformed and displaced. The force and motion of the particles follow the basic principle of Newton's law. The constitutive relation of the soil material can be realized by microcontact and bonding mode between particles. For homogeneous geotechnical materials, a large number of studies have shown that it is more reasonable to use the parallel bonding model $[11,19,20]$. In this regard, the parallel bond model is adopted in this paper, under which the particles have normal strength, tangential strength, normal stiffness, and tangential stiffness. Thus, it has the ability of antitension, antishear, and antitorsion. Normal stiffness and tangential stiffness can be expressed as [20] 


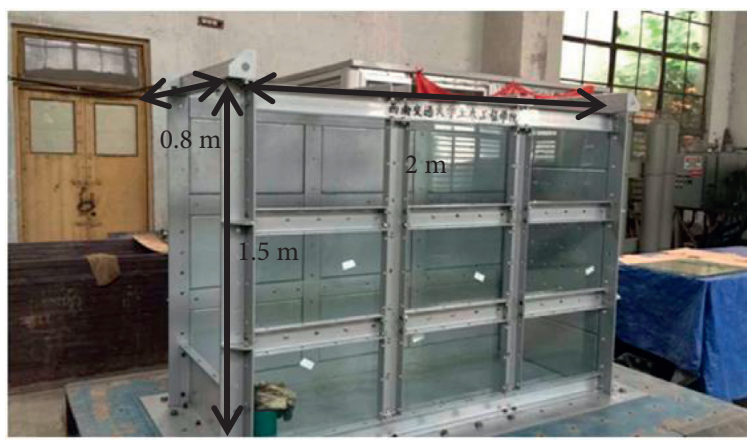

FIgURE 1: Schematic diagram of the model box.

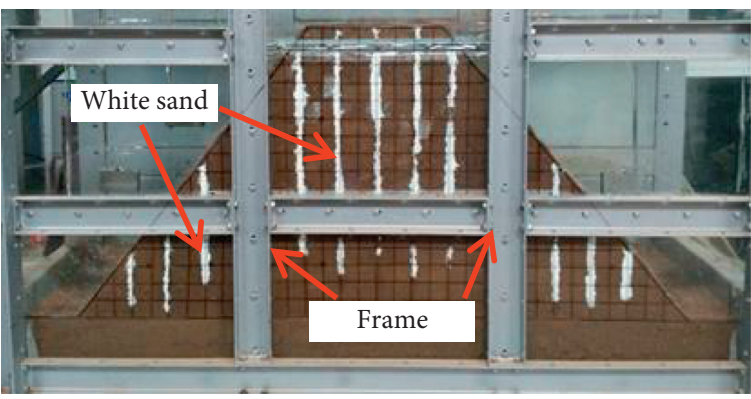

FIGURE 2: Shaking table test model of the double-side slope.

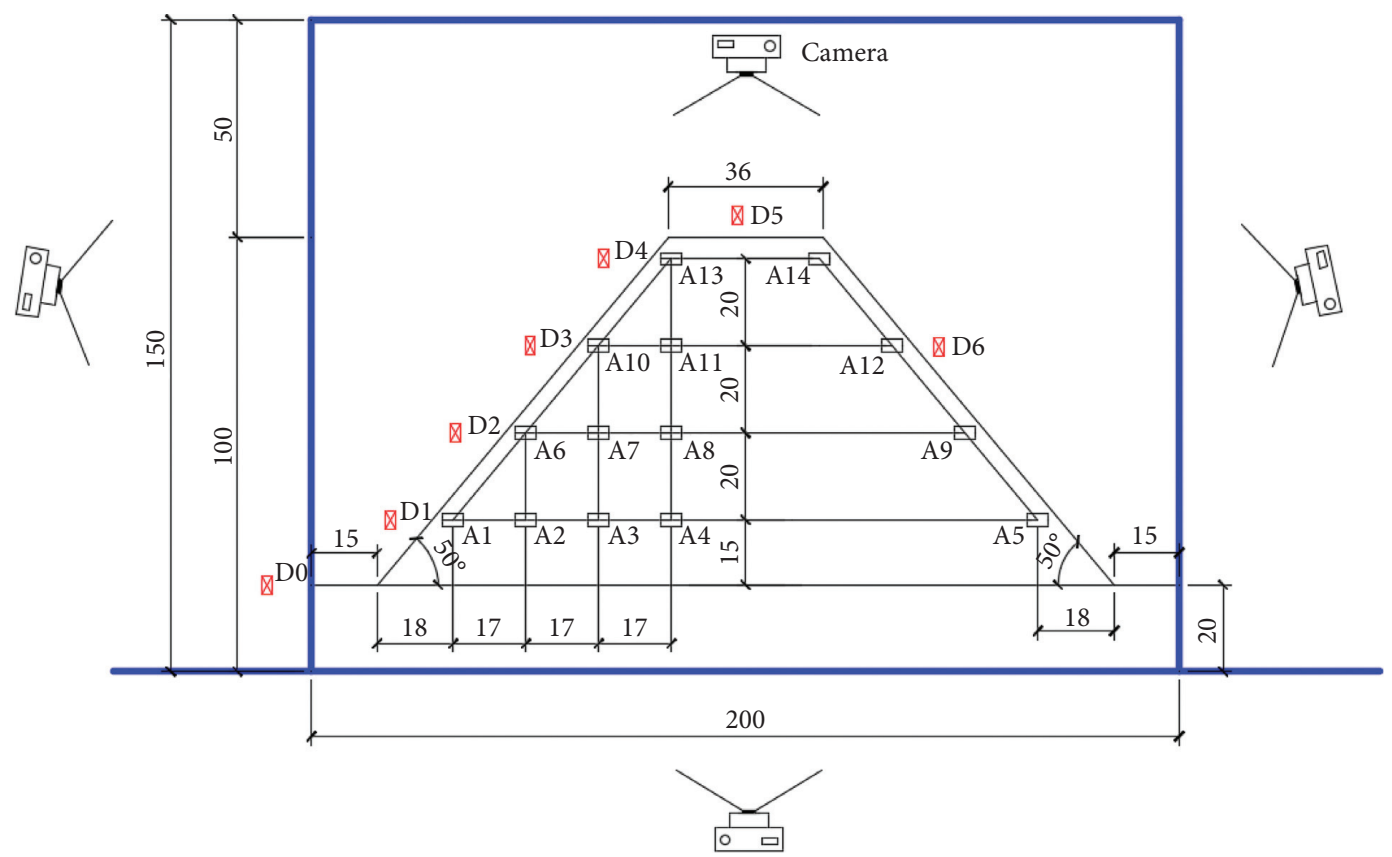

$\Xi$ Acceleration sensor

\ Laser displacement sensor

Figure 3: Layout of monitoring points. 


$$
\begin{aligned}
\bar{k}^{n} & =\frac{\bar{E}_{c}}{L}, \\
\bar{k}^{s} & =\frac{12 I \bar{E}_{c}}{A L^{3}}, \\
\bar{R} & =\bar{\lambda} \min \left(R^{[A]}, R^{[B]}\right), \\
A & =\pi \bar{R}^{2},
\end{aligned}
$$

where $\bar{k}^{n}$ is the normal contact stiffness, $\bar{k}^{s}$ is the tangential contact stiffness, $\bar{E}_{c}$ is Young's modulus of each parallel bond, $\bar{R}$ is the bond radius, $\bar{\lambda}$ is the radius multiplier used to set the parallel-bond radius, $L$ is the bond length, and $I$ is the moment of inertia.

The soil used in the test is a mixture of fine sand and clay at $1: 1$, with three kinds of moisture content of $5 \%, 8 \%$, and $12 \%$. The numerical model adopts the same soil parameters as the similar materials mentioned above, and the specific results are shown in Table 1.

3.2. Boundary Conditions and Ground Motion Input. In PFC, the wall represented by rigid lines is used as the basic unit. To prevent the dynamic force from reflecting at the boundary of the model, the wall at the bottom of the slope is set with a certain value of damping, and the damping force will be directly substituted into the equation of motion, as shown in equation (2). There are mainly viscous damping and local damping. In this paper, through a large number of trial calculations and sensitivity analyses, it is determined that the tangential and normal viscous damping is 0.157 and the local damping is 0.219:

$$
F_{(i)}+F_{(i)}^{d}=M_{(i)} A_{(i)},
$$

where $F_{(i)}, M_{(i)}$, and $A_{(i)}$ are generalized force, mass, and acceleration components, respectively, and $F_{(i)}^{d}$ is the damping force.

The field investigation shows that even in the extreme earthquake area of the Wenchuan earthquake, the horizontal seismic force plays a leading role in the instability of roadbed engineering [21]. Therefore, to simplify reasonably, only the horizontal ground acceleration is considered in this paper. A sine wave is used to simulate the excitation load. In PFC, acceleration cannot be applied directly to the slope, so it can only be done by applying velocity. That is, for $a=A \sin (2 \pi f t), v=-A \cos (2 \pi f) / 2 \pi f$, which is applied to the bottom of the slope. The load frequency is $3 \mathrm{~Hz}$, and the amplitude is in the range of $0.1 \mathrm{~g}$ to $0.6 \mathrm{~g}$. The failure of the slope is observed within the loading time of $12 \mathrm{~s}$. If there is no obvious damage, the slope is considered to be stable under this loading amplitude. Two geometric dimensions were used in the numerical model, one is consistent with the model test size, and the other is 10 times larger than the model test size. The numerical model and the location of the monitoring points are shown in Figure 4.

\section{Results and Discussion}

4.1. Slope Failure Process. Figure 5 shows the failure process of slopes with different water content under earthquakes. It can be seen from Figure 5 that the numerical simulation results are consistent with the shaking table test results, which shows the effectiveness of the numerical model in this paper. The failure process of the slope with $5 \%$ moisture content is that the soil slips along the shallow layer of the slope. A large vertical displacement occurs at the top of the slope, but no obvious horizontal displacement can be observed within the slope, indicating that the shear stress is not the main factor at this time. However, there are two obvious shear slip surfaces in the slope with $8 \%$ moisture content, which are almost symmetrical along the middle axis of the slope. When the slope is unstable, the shear failure occurs along the sliding surface. The failure mode can be described as the tensionshear-slip mode, which is the same as the failure mode of Wangjiayan and Daguangbao landslides in the Wenchuan earthquake [15]. With the increase of moisture content of $12 \%$, there is no obvious sliding surface within the slope when the slope fails. However, there are many cracks in the slope and the horizontal displacement in the slope is obvious when loading for $1 \mathrm{~s}$. The slope remains relatively stable until the loading time reached $3 \mathrm{~s}$, and the upper soil collapses and accumulates downward. In this condition, the shattering-collapse slip failure occurs in the slope, which is similar to the failure in the new area of the new Beichuan middle school [15]. Compared with the numerical simulation maps of the slope, it is obvious that, with the increase of moisture content, the distribution range and spacing of slope joints are expanding, and the settlement at the top of the slope is increasing. Based on the analysis of the failure mechanism of three kinds of slopes with different moisture content, it is found that, under the seismic load, the connection between surface soil particles is gradually destroyed, which results in the decreases of the tensile and shear strength. With the continuous vibration, the surface soil slips from the top to the bottom of the slope under the action of seismic force, accumulates at the foot of the slope, and slips on the shallow surface as a whole. Research studies show that, with the increase of soil moisture content, the dynamic shear modulus of soil decreases and the damping ratio is improved. So, the ability of soil to resist plastic deformation increases $[22,23]$. Shear failure occurs in the soil of $8 \%$ moisture content slope to form a continuous slip surface, and finally, the sliding body slips along the slip surface as a whole. For the slope with $12 \%$ moisture content, the dynamic shear modulus of the soil further is decreased, which results in serious damage of the soil by shearing stress. The obvious horizontal uneven dislocation can be seen in Figure 5(e). Consequently, the soil is cut into small pieces under the action of shear, and the stress is redistributed. With the increase of vibration time, instability and collapse occur. 
TABLE 1: Physical and mechanical parameters of soil.

\begin{tabular}{|c|c|c|c|c|c|c|c|}
\hline Case & $\begin{array}{c}\text { Moisture content } \\
(\%)\end{array}$ & $\begin{array}{l}\text { Density } \\
\left(\mathrm{g} / \mathrm{cm}^{3}\right)\end{array}$ & $\begin{array}{c}\text { Cohesion } \\
(\mathrm{kPa})\end{array}$ & $\begin{array}{c}\text { Internal friction } \\
\text { angle }\left({ }^{\circ}\right)\end{array}$ & $\begin{array}{l}\text { Young's modulus } \\
(\mathrm{MPa})\end{array}$ & $\begin{array}{l}\text { Plastic limit } \\
(\%)\end{array}$ & $\begin{array}{l}\text { Liquid limit } \\
\text { (\%) }\end{array}$ \\
\hline 1 & 5.0 & 1.5 & 7.5 & 32 & 15.1 & & \\
\hline 2 & 8.0 & 1.6 & 15.5 & 28 & 12.6 & 9 & 26 \\
\hline 3 & 12.0 & 1.7 & 20.0 & 20 & 7.7 & & \\
\hline
\end{tabular}

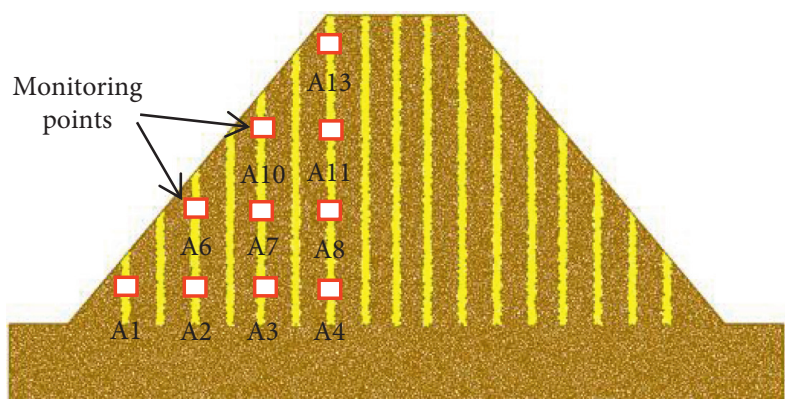

FIGURE 4: Geometrical model in numerical simulation.

4.2. Dynamic Response of Slope. To further explore the characteristics of slope failure under seismic load, the dynamic response of the slope was studied based on the surface monitoring points (A1, A6, A10, and A13). The displacement time-history curve and velocity time-history curve for the three groups of working conditions are shown in Figure 6 , in which the lines of monitoring point 1 , point 6 , point 10 , and point 13 are represented by black, red, blue, and green curves, respectively.

It can be seen from Figure 6 that the horizontal displacement of the slope with 5\% moisture content decreases with the increase of height. At $0.15 \mathrm{~s}$, the displacement and velocity have some changes. The velocity and displacement of monitoring points 1 and 6 were the largest, whose curves have roughly coincided with each other. Furthermore, a peak value occurs in the velocity time-history curve at this time and then decreases gradually, which tends to coincide with the peak value of the upper soil. The curves of monitoring points 10 and 13 are separated, and the displacement and velocity of monitoring point 13 are relatively small. Through the analysis of the time-history curves of velocity and displacement, there is a large slip at monitoring points 1 and 6 and a larger speed at the moment of sliding, and the bond between monitoring points 10 and 13 has been destroyed. The curves of monitoring points 1 and 6 did not separate until $0.8 \mathrm{~s}$, which indicates that although the displacement of the lower soil was larger than that of the upper soil, the loosening time of the internal soil of points 1 and 6 was later than that of the upper soil.

The slope with $8 \%$ moisture content is mainly affected by the shear failure, whose displacement and velocity timehistory curve abruptly change at $0.25 \mathrm{~s}$, and the velocity and displacement at monitoring point 13 decrease, while the curves of the other three monitoring points remain coincident. Combined with the analysis of Figures 5(c) and 5(d), it can be seen that the lower three points slide along the shear plane in the same sliding body, while the failure of the upper soil is due to the collapse of the lower soil. The displacement and velocity of monitoring point 1 suddenly increase at $2.25 \mathrm{~s}$, indicating that the soil at monitoring point 1 has slipped out from the original position. Besides, the displacement and velocity time-history curve of monitoring point 6 also increases sharply at $2.6 \mathrm{~s}$, indicating that when the soil at monitoring point 1 slips out from the original position, monitoring point 6 immediately slips out from the original position. It can be seen that the displacement timehistory curve for $8 \%$ moisture content is much denser than that for $5 \%$ water cut slope, which indicates that the damage degree of the bond between particles for $8 \%$ moisture content is lower than that for $5 \%$.

The displacement and velocity time history for $12 \%$ moisture content almost coincides before $2.25 \mathrm{~s}$, and the displacement increases steadily with the increase of vibration time, which shows that the bond failure between soil particles in the slope with $12 \%$ water content is lower. The transmission effect between particles is strong, and the relative sliding is not easy to occur between particles. After $2.25 \mathrm{~s}$, the displacement and velocity at monitoring points 1 and 6 suddenly increase and slip out from the original position, while the displacement and velocity at monitoring points 10 and 13 still maintained a relatively stable development.

By comparing the displacement and velocity time-history curves for the three kinds of moisture content, it can be found that the displacement and velocity for 5\% moisture content are significantly smaller than that of $8 \%$ and $12 \%$. The displacement of the monitoring point is related to the velocity of nearby soil particles. During the failure of the slope with $5 \%$ moisture content, the amplitude of the input sine wave is small, and the whole vibration of the slope is lower. The horizontal seismic force does less work to the soil particles. For this reason, the bond between the soil particles in the shallow topsoil for the 5\% moisture content is destroyed into a loose accumulation. In addition, it can be 

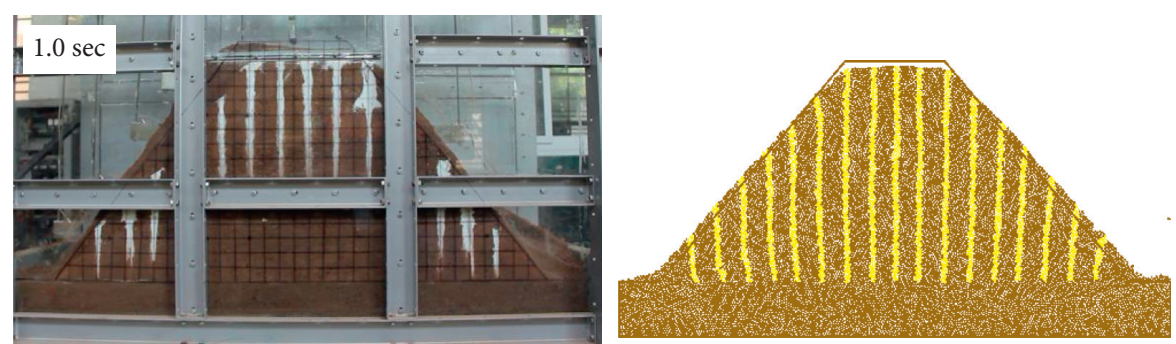

(a)
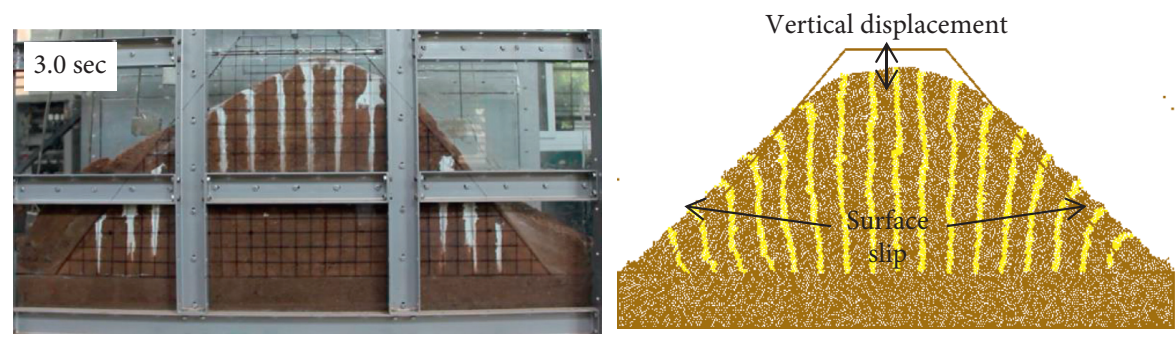

(b)
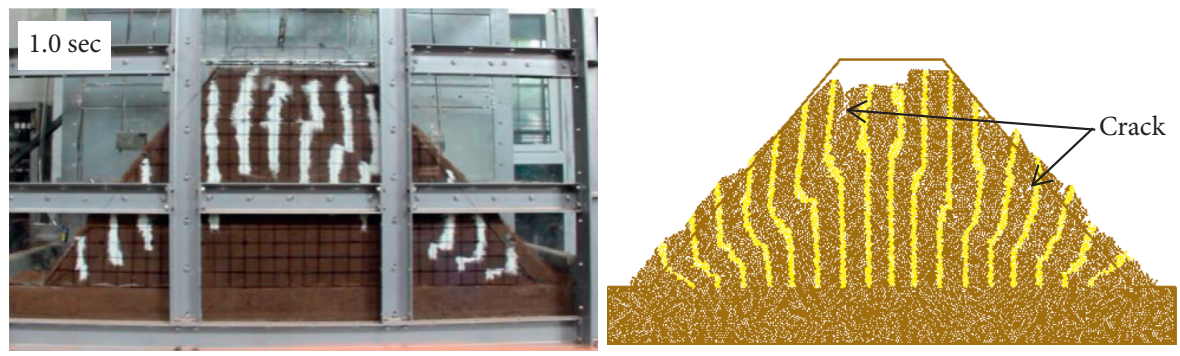

(c)
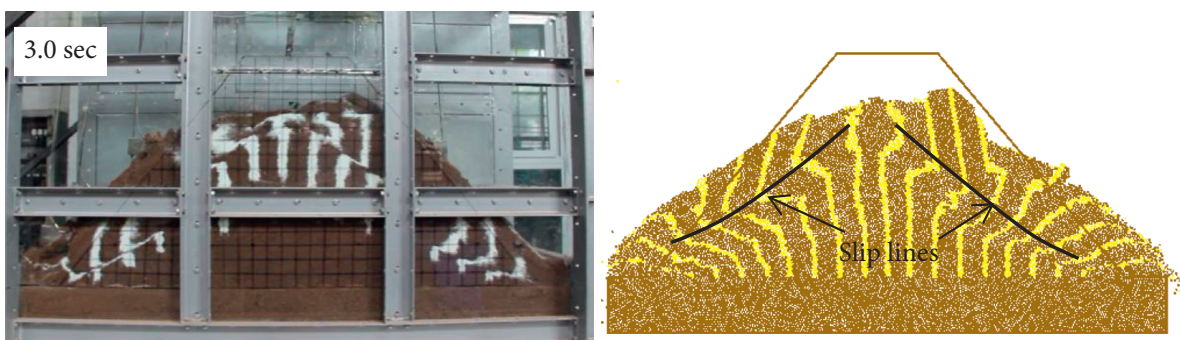

(d)
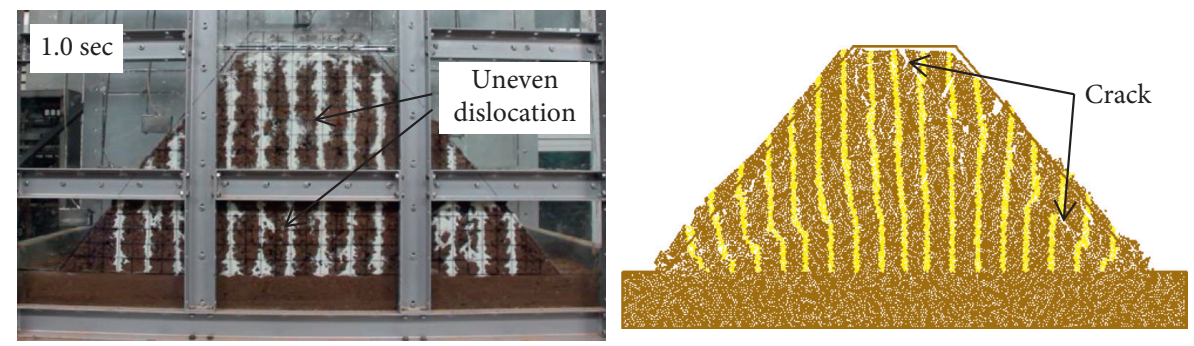

(e)
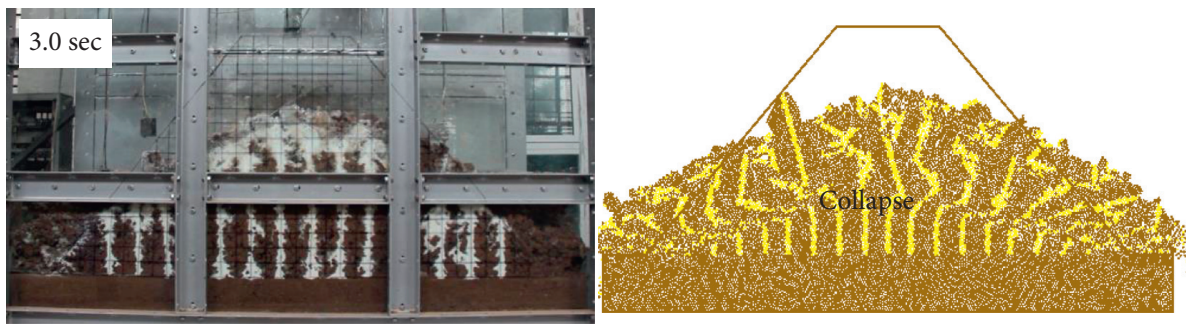

(f)

Figure 5: Comparison of results by model test and numerical simulation. (a) Failure when loading $1 \mathrm{~s}$ (5\% moisture content). (b) Failure when loading $3 \mathrm{~s}$ ( $5 \%$ moisture content). (c) Failure when loading $1 \mathrm{~s}$ (8\% moisture content). (d) Failure when loading $3 \mathrm{~s}$ ( $8 \%$ moisture content). (e) Failure when loading $1 \mathrm{~s}$ (12\% moisture content). (f) Failure when loading $3 \mathrm{~s}$ (12\% moisture content). 


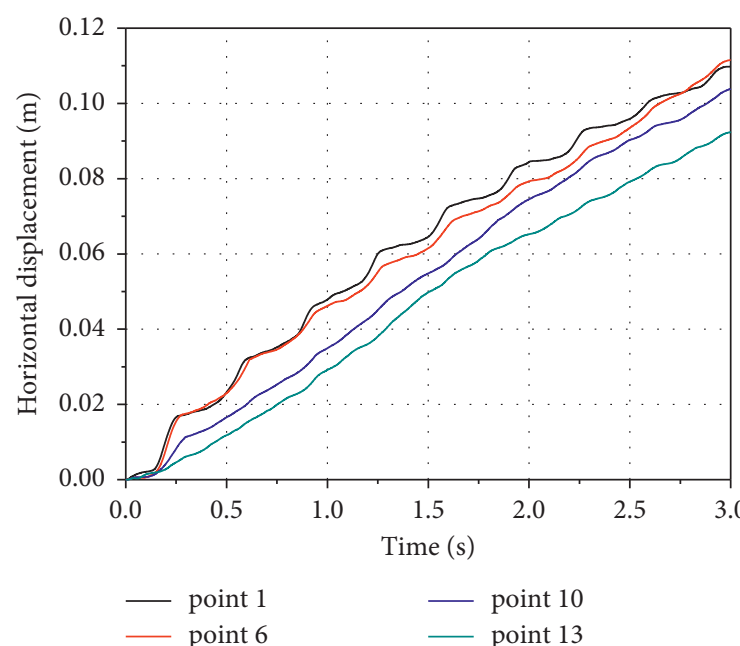

(a)

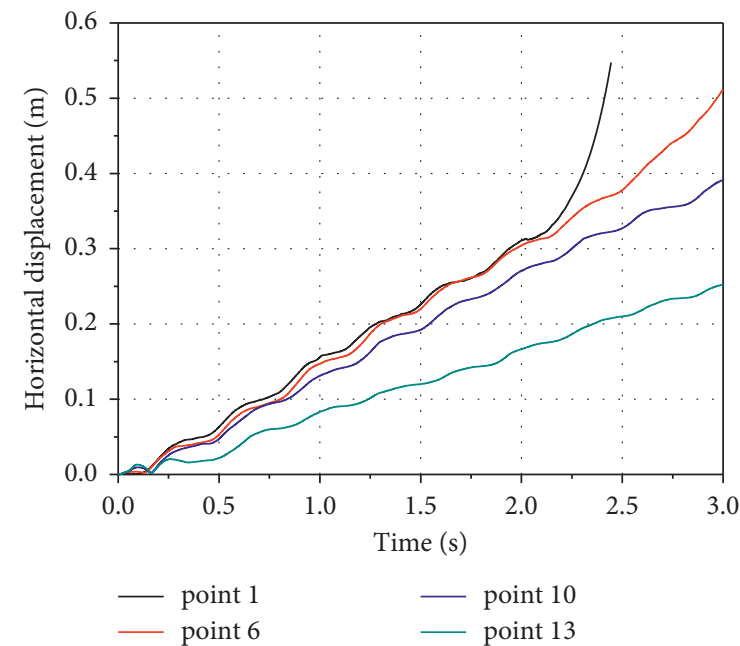

(c)

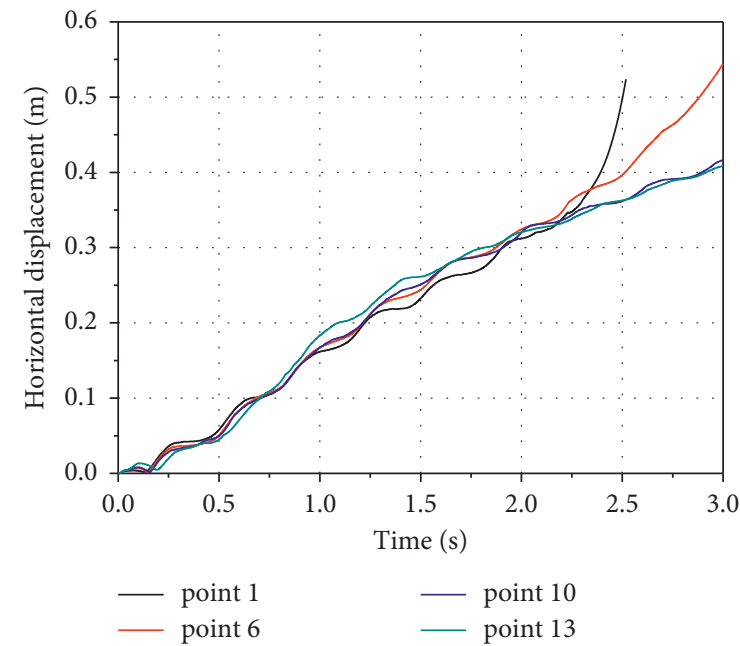

(e)

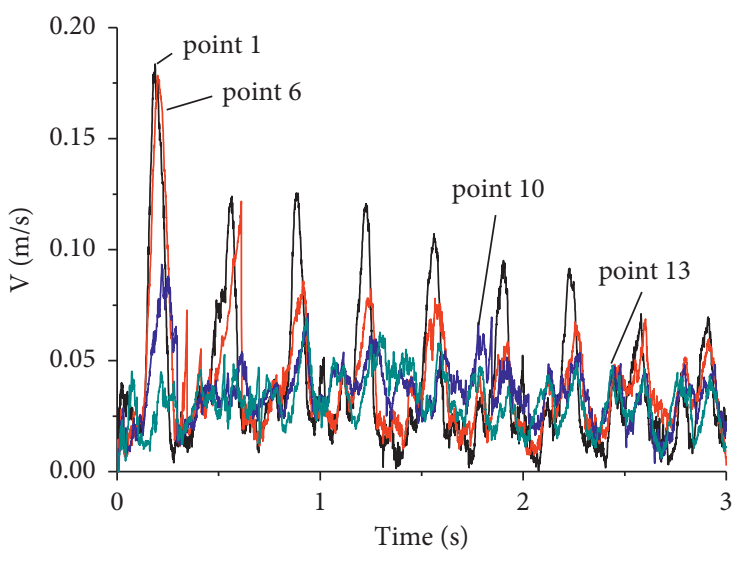

(b)

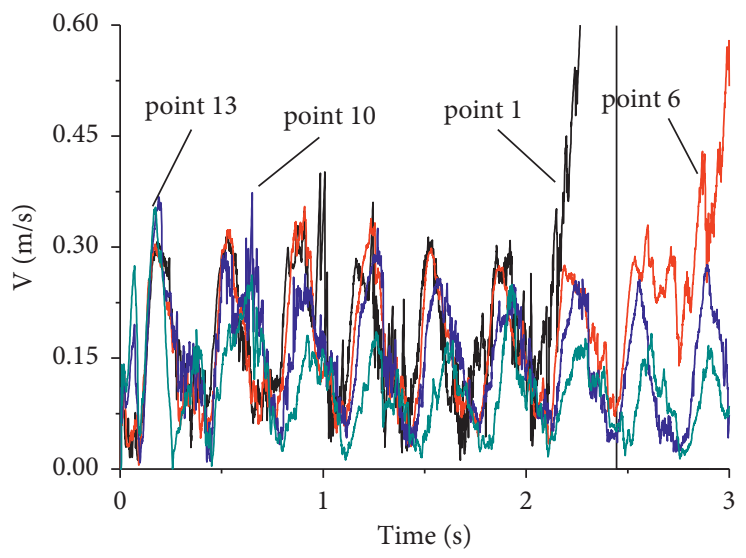

(d)

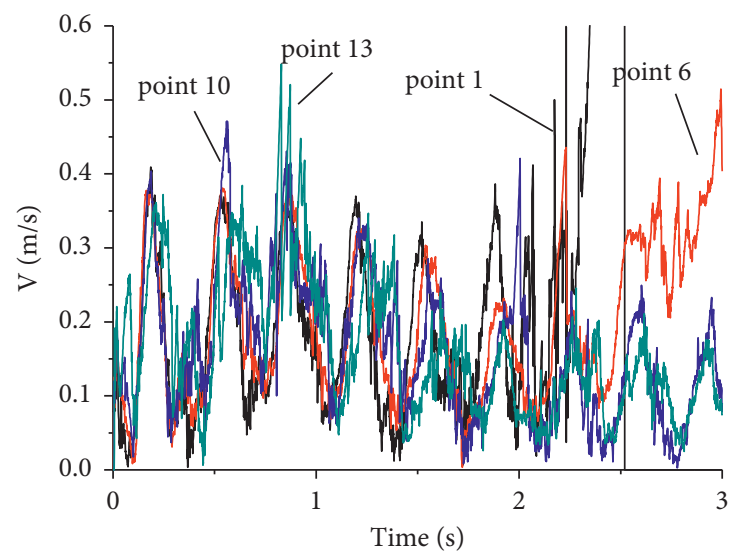

(f)

FIgURE 6: Displacement and velocity time history of monitoring points in the slope under different moisture contents. (a) Displacement curve at 5\% moisture content. (b) Velocity curve of 5\% moisture content. (c) Displacement curve of $8 \%$ moisture content. (d) Velocity curve of $8 \%$ moisture content. (e) Displacement curve of $12 \%$ moisture content. (f) Velocity curve of $12 \%$ moisture content. 


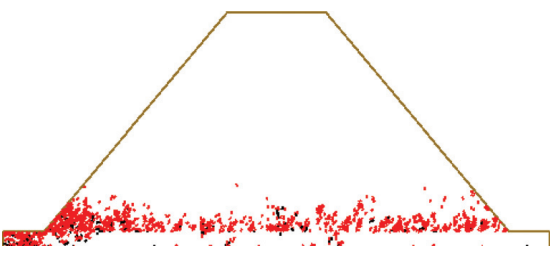

(a)

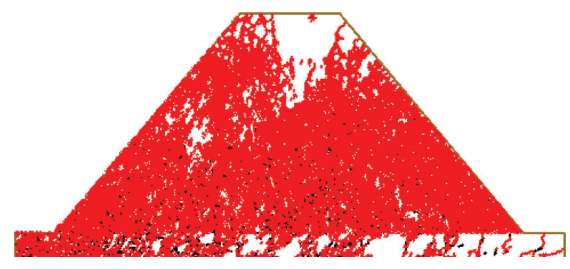

(c)

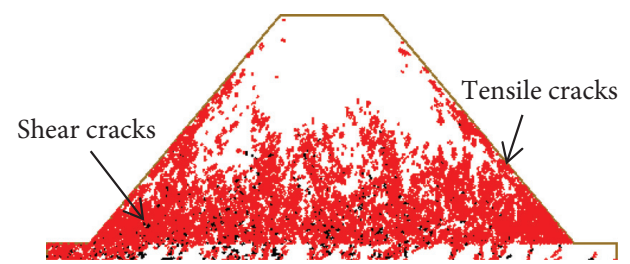

(b)

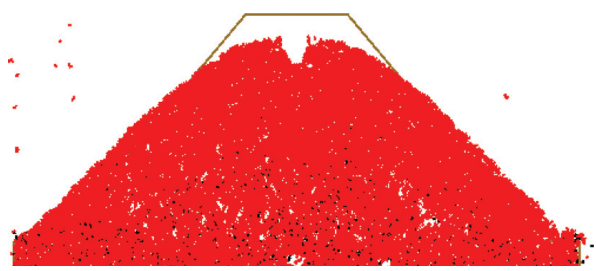

(d)

Figure 7: Crack development process in the slope with 5\% moisture content. (a) At loading $0.1 \mathrm{~s}$. (b) At loading $0.3 \mathrm{~s}$. (c) At loading $0.5 \mathrm{~s}$. (d) At loading $3 \mathrm{~s}$.

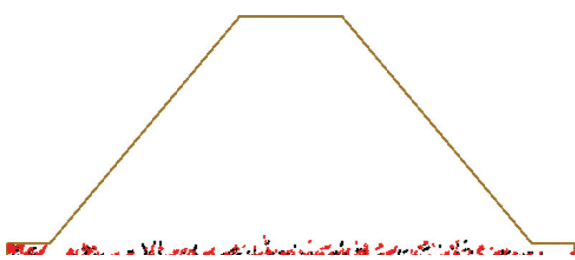

(a)

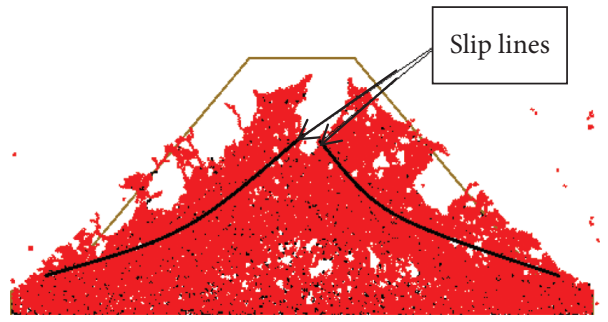

(c)

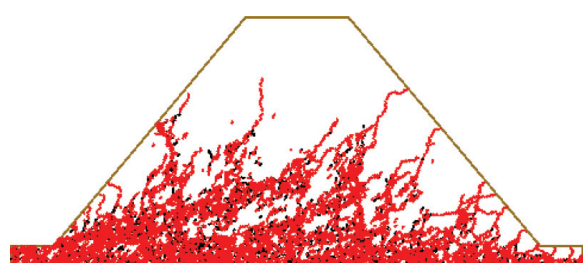

(b)

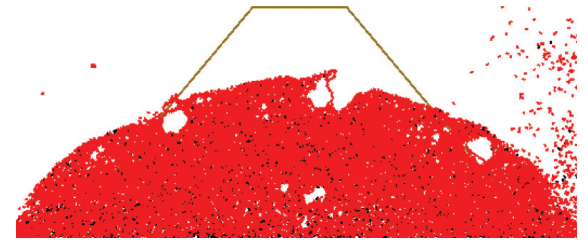

(d)

FIGURE 8: Crack development process with $8 \%$ moisture content. (a) At loading $0.1 \mathrm{~s}$. (b) At loading $0.5 \mathrm{~s}$. (c) At loading $1 \mathrm{~s}$. (d) At loading $3 \mathrm{~s}$.

seen from Figure 5 that the slope with $5 \%$ moisture content has a shallow surface slip, and the interior of the slope is relatively stable.

Based on the above analysis, with the increase of moisture content, the displacement time-history curves of the slope become closer, and the velocity time-history curve before failure is relatively much closer, indicating that the relative motion between particles is reduced.

4.3. Development Process of Microfissures. $\mathrm{PFC}^{2 \mathrm{D}}$ can simulate the development process of interparticle fracture. The normal bond failure between particles leads to tensile failure, and tangential bond failure leads to shear failure. In this section, black represents the crack caused by shear failure and red indicates the crack caused by tension.

It can be seen from Figure 7 that the cracks in the slope with 5\% moisture content develop rapidly, and shear cracks are mainly in the lower part of the slope. From the previous analysis, the slope began to slide at $0.1 \mathrm{~s}$. There are only tensile cracks in the shallow part of the slope at $0.3 \mathrm{~s}$, and the shear cracks are concentrated at the toe of the slope. The displacement and velocity time-history curves at monitoring points 1 and 6 remain coincident at 0.15 seconds, which shows that the soil at the lower part does not split yet, while the separation of the curves at the upper monitoring points 10 and 13 indicates that the soil around the monitoring point 10 and 13 has become loose due to tension. At $0.5 \mathrm{~s}$, more tensile cracks get developed in the lower shear region, which plays a leading role in the slope failure. The displacement and velocity time-history curves at monitoring points 1 and 6 are separated, which shows that the soil slides under the action of seismic force and self-weight stress. Overall, the slope with 5\% moisture content is relatively loose. At the initial stage, the tensile damage of the slope surface is serious. The development of 


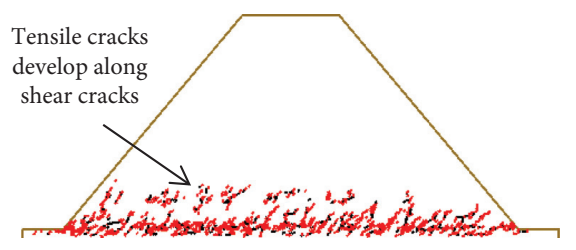

(a)

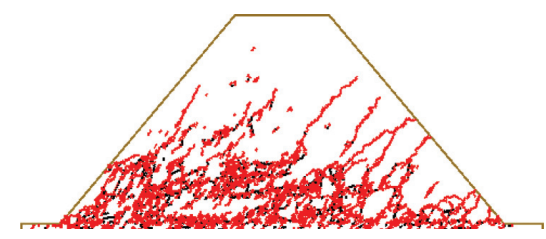

(b)

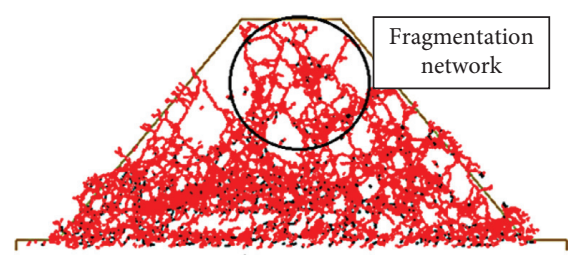

(c)

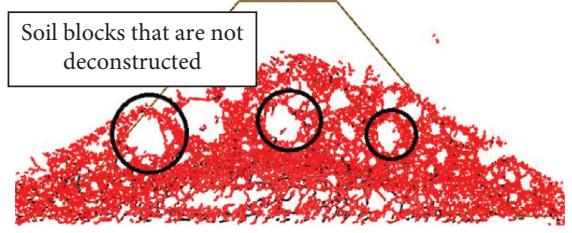

(d)

Figure 9: Crack development process with 12\% moisture content. (a) At loading $0.1 \mathrm{~s}$. (b) At loading $0.5 \mathrm{~s}$. (c) At loading $1 \mathrm{~s}$. (d) At loading $3 \mathrm{~s}$.

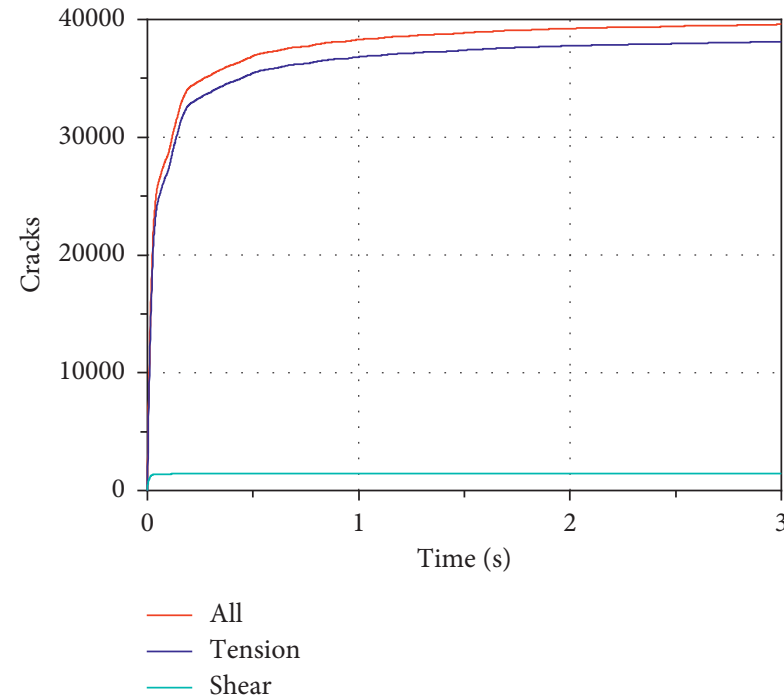

(a)

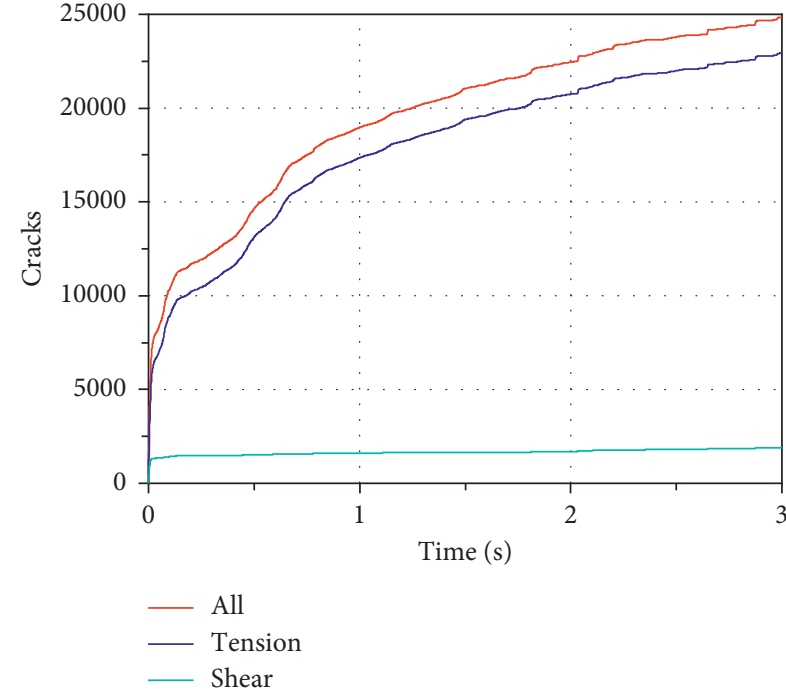

(b)

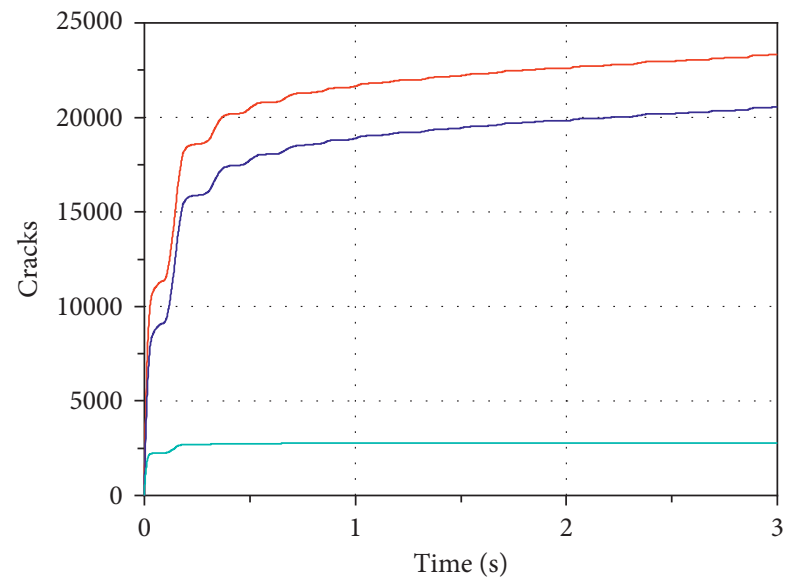

All
Tension
Shear

(c)

Figure 10: Fracture development curve. (a) For 5\% moisture content. (b) For 8\% moisture content. (c) For 12\% moisture content. 
tensile cracks in the upper part of the slope causes the damage of the bond between particles, and the soil at the toe of the slope slides as a whole due to local shearing. In a very short time, the development of the tensile cracks at the slope toe and the destruction of the bond between particles lead to slope failure under the action of earthquakes and self-weight stress. The failure mode of the slope with $5 \%$ moisture content is shattering-shallow sliding.

From Figure 8, it can be seen that the failure of the slope is related to the connection of the local shear failure surface. When loading for $0.5 \mathrm{~s}$, it can be seen that the small cracks firstly propagate upward, and the tensile cracks develop along the shear cracks. As can be seen from Figure 6(c), at $0.5 \mathrm{~s}$, the displacement time-history curve of monitoring point 13 has been separated from the other three curves, indicating that the overall local shear slip has occurred in the lower part of the slope. At this time, the integrity of the soil at the top of the slope is great, indicating that a small amount of settlement has taken place on the top of the slope. When loading for $1 \mathrm{~s}$, the local shear plane runs through the slope to form the slip surface, and the slip lines intersected at the lower part of the crest of the slope. With the increase of vibration time, the soil on the crest collapses downward with the sliding of the soil on the two sides of the slope.

From Figure 9, it can be seen that the shear cracks develop radially from the bottom of the slope to the top, and the tensile cracks develop along the shear crack. After loading for $1 \mathrm{~s}$, the soil inside the slope breaks up into soil blocks of different sizes, forming a fracture network. It can be seen from Figure 6(e) that the displacement time-history curves of the monitoring points of the slope nearly coincide before failure. With the increase of loading time, uneven dislocation occurs in the interior of the slope, leading to the collapse of the slope.

4.4. Development of Cracks' Number in Slope. Fractures include tensile cracks and shear cracks. As can be seen from Figure 10, with the increase of moisture content, the number of fractures and tensile cracks at slope failure gradually decreases, while the shear cracks increase. This shows that tensile cracks mainly developed in the interior of the slope under the action of earthquakes, but are not necessarily the main factor causing damage. The slope with $5 \%$ moisture content is relatively loose, and the tensile failure occurs easily under the earthquake. While for $8 \%$ and $12 \%$ moisture content, the double-sided slopes are damaged mainly by shearing stress. From Figures 10(a) and 10(c), it can be seen that the fractures' number in the slope with $5 \%$ and $12 \%$ moisture content is relatively stable when loading time is $1 \mathrm{~s}$ and increases slowly with the increase of vibration time. The shear slip occurs in the slope with $8 \%$ moisture content, and the cracks increase gradually during the sliding of the slope. In short, with the increase of moisture content, the ability of the slope to resist tensile crack increases, so attention should be paid to shear failure in slope reinforcement.

\section{Conclusions}

In this paper, the failure mode and mechanism of multiface slopes with different moisture content under earthquake action were studied by using a two-dimensional particle flow program $\left(\mathrm{PFC}^{2 \mathrm{D}}\right)$. The following conclusions can be drawn:

(1) The failure modes of slopes with different moisture content under earthquake action are different. The failure mode of the slope with 5\% moisture content is shattering-shallow sliding, and the failure mode of slopes with $8 \%$ moisture content is tension-shearslip, and shattering-collapse slip failure occurs at $12 \%$ moisture content.

(2) The failure of a multiface slope is a gradual failure process under the action of earthquakes. The shallow layer of the slope with $5 \%$ moisture content is seriously damaged by tension under the action of earthquakes; the upper part of the slope is unstable due to the damage of the bond between particles. For the slope with $8 \%$ moisture content under the action of earthquakes, there are shear cracks developed inside the slope. With the increase of vibration time, the local shear failure plane runs through into a slip plane, and the slope slides along the slip surface. Under the action of earthquakes, a fracture network develops in the slope with $12 \%$ moisture content due to shear failure inside the slope.

(3) With the increase of water content, the fractures and tensile cracks in the slope decrease gradually, while the shear cracks increase gradually. In the case of low moisture content, the tensile cracks play a leading role in the failure of the slope. With the increase of moisture content, the influence of shear failure on slope failure is increasing, and more efforts should be placed on reducing the shear cracks.

\section{Data Availability}

The data used to support the findings of this study are available from the corresponding author upon request.

\section{Conflicts of Interest}

The authors declare that they have no conflicts of interest.

\section{Acknowledgments}

This study was supported by Sichuan Science and Technology Program (2021YFS0323 and 2020YFG0123).

\section{References}

[1] R. Huang and W. Li, "Development and distribution of geohazards triggered by the 5.12 Wenchuan earthquake in China," Science in China-Series E: Technological Sciences, vol. 52, no. 4, pp. 810-819, 2009.

[2] R. Q. Huang and W. L. Li, "Analysis of the geo-hazards triggered by the 12 May 2008 Wenchuan earthquake, China," 
Bulletin of Engineering Geology and the Environment, vol. 68, no. 3, pp. 363-371, 2009.

[3] J. Wasowski, D. K. Keefer, and C.-T. Lee, "Toward the next generation of research on earthquake-induced landslides: current issues and future challenges," Engineering Geology, vol. 122, no. 1-2, pp. 1-8, 2011.

[4] B. Yang, F.-p. Gao, and D.-s. Jeng, "Failure mode and dynamic response of a double-sided slope with high water content of soil," Journal of Mountain Science, vol. 15, no. 4, pp. 859-870, 2018.

[5] J. Huang, M. Zhao, C. Xu, X. Du, L. Jin, and X. Zhao, "Seismic stability of jointed rock slopes under obliquely incident earthquake waves," Earthquake Engineering and Engineering Vibration, vol. 17, no. 3, pp. 527-539, 2018.

[6] M. Ehteshami-Moinabadi and S. Nasiri, "Geometrical and structural set-ting of landslide dams of the central Alborz: a link between earth- quakes and landslide damming," Bulletin of Engineering Geology and the Environment, vol. 78, 2017.

[7] G. Fan, J. Zhang, J. Wu, and K. Yan, "Dynamic response and dynamic failure mode of a weak intercalated rock slope using a shaking table," Rock Mechanics and Rock Engineering, vol. 49, no. 8, pp. 3243-3256, 2016.

[8] X. Liu, C. He, S. Liu, Y. Liu, Y. Lu, and Z. Liu, "Dynamic response and failure mode of slopes with horizontal soft and hard interbeddings under frequent microseisms," Arabian Journal for Science and Engineering, vol. 43, no. 10, pp. 5397-5411, 2018.

[9] H.-B. Li, X.-W. Li, Y. Ning, S.-F. Jiang, and J.-W. Zhou, "Dynamical process of the Hongshiyan landslide induced by the 2014 Ludian earthquake and stability evaluation of the back scarp of the remnant slope," Bulletin of Engineering Geology and the Environment, vol. 78, no. 3, pp. 2081-2092, 2019.

[10] Z. Deng, X. Liu, Y. Liu et al., "Cumulative damage evolution and failure modes of the bedding rock slope under frequent microseisms," Arabian Journal of Geosciences, vol. 13, no. 10, 2020.

[11] J. Hou, M. Zhang, Q. Chen, D. Wang, J. Akbar, and S. Zhang, "Failure-Mode analysis of loose deposit slope in ya'ankangding expressway under seismic loading using particle flow code," Granular Matter, vol. 21, no. 1, pp. 1-12, 2019.

[12] K. Abe, S. Nakamura, H. Nakamura, and K. Shiomi, "Numerical study on dynamic behavior of slope models including weak layers from deformation to failure using material point method," Soils and Foundations, vol. 57, pp. 155-175, 2017.

[13] K. J. Chang and A. Taboada, "Discrete element simulation of the Jiufengershan rock-and-soil avalanche triggered by the 1999 Chi-Chi earthquake, Taiwan," Journal of Geophysical Research: Earth Surface, vol. 114, pp. 2003-2012, 2009.

[14] C. L. Tang, J. C. Hu, M. L. Lin et al., "The Tsaoling landslide triggered by the Chi-Chi earthquake, Taiwan: insights from a discrete element simulation," Engineering Geology, vol. 106, no. 1, pp. 1-19, 2009.

[15] R. Huang, Q. Xu, and J. Huo, "Mechanism and geo-mechanics models of landslides triggered by 5.12 Wenchuan earthquake," Journal of Mountain Science, vol. 8, no. 2, pp. 200-210, 2011.

[16] Y. Changwei, X. Liu, J. Zhang, Z. Chen, C. Shi, and H. Gao, "Analysis on mechanism of landslides under ground shaking: a typical landslide in the Wenchuan earthquake," Environmental Earth Sciences, vol. 72, no. 9, pp. 3457-3466, 2014.

[17] R. Xiao, Q. Xu, W. Feng, J. Chen, and Y. Zuo, "Study on deformation and failure mechanism of double slope under strong earthquake conditions by shaking table physical simulation test," Journal of Engineering Geology, vol. 18, no. 6, pp. 837-843, 2010.

[18] P. A. Cundall and O. D. L. Strack, "A discrete numerical for granular assemblies,” Geotechnique, vol. 29, no. 1, pp. 47-65, 1979.

[19] J. Zhou, P. Cui, and H. Fang, "Dynamic process analysis for the formation of Yangjiagou landslide-dammed lake triggered by the Wenchuan earthquake, China," Landslides, vol. 10, no. 3, pp. 331-342, 2013.

[20] J. He, X. Li, S. Li, Y. Yin, and H. Qian, "Study of seismic response of colluvium accumulation slope by particle flow code," Granular Matter, vol. 12, no. 5, 2010.

[21] L. Yao and Q. Chen, "A new topic on seismic technology of line engineering caused by "5.12" Wenchuan earthquake," Journal of Sichuan University (Engineering Science Edition), vol. 41, no. 3, pp. 43-50, 2009.

[22] Y. Chen, M. Irfan, T. Uchimura, Q. Meng, and J. Dou, "Relationship between water content, shear deformation, and elastic wave velocity through unsaturated soil slope," Bulletin of Engineering Geology and the Environment, vol. 79, no. 8, pp. 4107-4121, 2020.

[23] S. Zhao, Y. Zhu, P. He, and D. Wang, "Measurement of dynamic parameters of frozen soil," Journal of Rock Mechanics and Engineering, vol. 22, no. S2, pp. 2677-2681, 2003, in Chinese. 